\section{Crianças e línguas indígenas: contribuições para o debate sobre o deslocamento linguístico em comunidades indígenas urbanas}

\section{Por María Macarena Ossola}

Universidad Nacional de Salta - CONICET (maca_ossola@yahoo.com.ar)

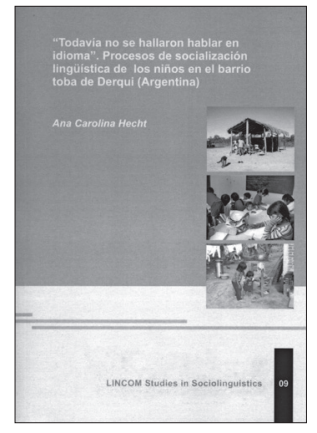

HECHT, Ana Carolina. "Todavía no se hallaron hablar en idioma". Procesos de socialización lingüística de los niños en el barrio toba de Derqui (Argentina). Munich: LINCOM Europa Academic Publisher, 2010. (LINCOM Studies in Sociolinguistics, 9). 282 p. ISBN 978-389586-361-5

“'Todavía no se hallaron hablar en idioma'. Procesos de socialización lingüística de los niños en el barrio toba de Derqui (Argentina)" é uma versão revisada da tese doutoral da autora, defendida na Faculdade de Filosofia e Letras da Universidade de Buenos Aires (2009), e adaptada para a divulgação no formato de livro. O principal propósito da tese consiste em dar conta dos modos em que se usam e representam a língua indígena toba e o espanhol nas interações cotidianas de uma população Toba, composta por famílias migrantes que moram em um bairro situado em Derqui, província de Buenos Aires.

Os Toba, cujo etnônimo é Qompi, integram o grupo étnico e linguístico chamado Guaycurú (Messineo, 2003). A população Toba na Argentina é estimada em 69.452 pessoas, segundo dados da "Encuesta Complementaria de Pueblos Indígenas" (ECPI), realizada durante 2004 e 2005. Os Toba moravam em bandas bilaterais nômades compostas por famílias extensas que se dedicavam à caça e à coleta na região do Gran Chaco (Miller, 1979). A partir do século XIX, suas condições de vida foram cada vez mais adversas, iniciando-se o processo de desterritorialização e migração para as grandes cidades da Argentina, onde atualmente muitos deles moram e reivindicam seus direitos coletivos (Wright, 1999; Tamagno, 2001).

Em primeiro lugar, é preciso destacar que se trata de um livro que sintetiza o prolongado trabalho de campo feito pela autora na região, período no qual se dedicou não só à pesquisa, mas também coordenou oficinas de língua toba e fez enquetes, entre outras atividades. Por isso, o trabalho tem a riqueza de ser, ao mesmo tempo, o produto de um processo formativo, uma amostra de trabalho etnográfico reflexivo e a síntese da triangulação possível entre pesquisa e transferência.

A obra se organiza em quatro eixos, composto cada um por dois ou três capítulos, respectivamente. $O$ primeiro eixo, intitulado " ¿(Dis)continuidades lingüísticas y culturales? Entre la perspectiva sociolingüística y la antropológica", repassa as explicações formuladas desde a sociolinguística e a antropologia linguística a respeito dos processos de deslocamento das línguas. Ela parte da formulação da pergunta: o que leva um grupo de falantes a mudar o uso de uma língua (toba) por outra (espanhol)? Então, faz uma detalhada descrição das teorias que intentaram fornecer as respostas a essa questão. Assim, a autora define três aspectos de relevância para a obra toda. Por uma parte, explicita sua intenção etnográfica: a etnografia é uma estratégia que não só lhe permite se centrar na cotidianidade da substituição linguística, mas também se colocar corretamente no debate a respeito da dualidade entre a análise macrossocial e a análise microssocial. Simultaneamente, destaca a complexidade do estudo dos processos de socialização, colocando as crianças como sujeitos ativos na transmissão de conhecimentos entre gerações. Finalmente, situa a linguagem em uma esfera social, política e cultural estendida.

"Entre el Chaco y Buenos Aires. Aproximación etnográfica y sociolingüística al barrio toba de Derqui" é o titulo do segundo eixo. Além de descrever as características físicas do bairro e as características fonológicas e morfológicas da língua toba (cujo etnônimo 
é qom l'aqtaqa, o idioma dos qom), esse capítulo oferece a oportunidade de conhecer como território(s), língua(s) e sentimentos de comunidade se encontram relacionados intimamente. A história do bairro toba de Derqui inicia-se no ano 1995 (quando sua edificação começou) e sua extensão física materializa-se nas trinta e duas casas que o compõem. Desse modo, a etnografia da autora aponta para a análise processual e nos remonta à história dos tobas habitantes do Gran Chaco e aos modos como essa história não só se recria nas interações cotidianas em Derqui, mas também como ela permeia os atuais processos de socialização e transmissão de conhecimentos entre gerações. A ênfase na desfolclorização e na desessencialização que a autora coloca ao traçar processos sociais vivenciados pelos moradores do bairro encontra-se presente também no momento de analisar as línguas. Assim, entrecruzando fragmentos de entrevistas com os vizinhos de Derqui, a autora refaz os espaços, os tons e os modos de uso de cada uma das línguas em contextos particulares.

O terceiro eixo, "Socialización en y a través del toba y el español durante la niñez", é composto por três capítulos. Os dois primeiros ocupam-se do estudo das especificidades com que é percebida a infância como etapa do ciclo vital, de acordo com a perspectiva toba, ao tempo em que aprofunda sobre os tipos de atos comunicativos que privilegiam o uso de uma ou de outra língua segundo o contexto, a posição social e a idade das pessoas que intervêm na comunicação. Assinala-se, por exemplo, que, embora o deslocamento do toba para o espanhol seja constante, existem âmbitos nos quais a comunicação é realizada exclusivamente em toba (por exemplo, entre idosos emigrados da província do Chaco), ou com emissões em toba e respostas no espanhol (como no caso dos mandados ou ordens cotidianas que os pais indicam para seus filhos). A autora descreve também os espaços onde as interações se produzem exclusivamente em espanhol, como as que as crianças mantêm entre si, com crianças dos outros bairros e com adultos e crianças no âmbito escolar.
Dada à centralidade que tem esse último espaço formativo na configuração da identidade, no capítulo sete analisam-se os sentidos dados à experiência escolar por parte das crianças, complementando-os com as perspectivas das famílias, dos docentes e dos administradores. O título do capítulo, "Encrucijadas en la escuela”, faz uma síntese dos complexos processos experimentados pelas crianças em uma instituição educacional de nível primário, onde são interpeladas pelos docentes a partir de seu pertencimento étnico e pelas supostas dificuldades que também trouxe seu bilinguismo, entre outras representações. Simultaneamente, a autora nos mostra o quanto as famílias valorizam a escola como o espaço adequado para aprender o espanhol (particularmente a escrita), confiando em que o correto uso dessa língua permitirá a seus filhos terem acesso a melhores posições no mercado de trabalho e a projetos de vida mais amplos.

No último eixo, "Distancias lingüísticas, distancias generacionales. Reflexiones acerca del papel del habla en la vida social", se faz uma proposta para a leitura dos dados apresentados, a partir da união, em duas ideologias linguísticas, das representações que os adultos têm a respeito da fraqueza do uso do toba nas crianças. Assim, uma "ideologia do receio" condensa aqueles sentidos que observam a troca do toba pelo espanhol como um processo irreversível, ao tempo em que desde uma "ideologia do anseio" se coloca nas crianças a esperança de uma revitalização futura da língua toba.

Com a claridade e consistência que caracterizam o livro, Hecht nos oferece uma conclusão na qual são apresentados os resultados da pesquisa. Eles nos fazem um convite para refletir sobre as ideias nativas com relação às necessidades comunicativas das crianças em um cenário complexo, atravessado pelos repertórios linguísticos em toba e em espanhol. Nessa seção, fica explícita a contribuição do livro nas suas duas direções principais: de um lado, (a) o avanço na documentação dos processos de socialização linguística a partir das

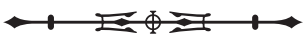


construções de sentido feitas pelas próprias crianças e, do outro lado, (b) a utilização de uma perspectiva etnográfica que permite configurar uma leitura renovada e criativa nas discussões sobre o deslocamento linguístico e a perda das línguas indígenas.

Com relação ao primeiro ponto (a), a autora nos apresenta uma proposta original para realizar o trabalho etnográfico com e entre meninos e meninas. A estratégia de lançar mão, primeiramente, das perspectivas nativas, ao invés de recorrer às categorias sociológicas no que diz respeito às classificações etárias, nos introduz em uma leitura onde tanto a 'infância' como seus atributos são compreendidos como construções feitas desde a própria práxis etnográfica. Assim, o livro traz uma valiosa contribuição ao conhecimento dos usos das línguas a partir do olhar das crianças de Derqui, demonstrando que eles ocupam uma posição dinâmica nos processos de transmissão cultural, organizando ativamente a informação que lhes é comunicada, e articulando uma concepção própria da sua identidade.

Em paralelo, a obra avança no campo da etnolinguística contemporânea ao oferecer uma perspectiva renovada dentro do debate a respeito da perda das línguas indígenas (b). Desse modo, ao estudar os processos de socialização das crianças tobas de Derqui, a autora sublinha que, frente às visões duais que proclamam a irreversível perda da(s) língua(s) indígena(s), de um lado, e a esperança da revitalização e do 'retorno às origens', do outro, existem múltiplos espaços locais onde as pessoas e os grupos participam ativamente da criação, do uso e da ressignificação dos elementos linguísticos. Os mesmos provêm de diferentes contextos e são válidos enquanto tornarem possível a comunicação cotidiana e a elaboração de projetos de vida e de identidade comum.
"Todavía no se hallaron hablar en idioma" é um livro que nos coloca frente às complexidades dos processos linguístico-culturais vivenciados pelas comunidades indígenas argentinas contemporâneas. A partir da análise do bairro toba de Derqui e das línguas que ali são utilizadas, a etnografia de Hecht nos mostra o contexto de redefinições (linguísticas, identitárias, geográficas, educativas) no qual essas populações se encontram atravessando e disputando. Com base em um rigoroso registro do campo etnográfico, a autora afirma que as análises sociais referidas ao deslocamento linguístico devem ser lidas no marco das disputas e tensões interculturais de maior escala, levando em conta que as práticas linguísticas - enquanto práticas sociais - se encontram estreitamente relacionadas com outras (políticas, socioculturais e econômicas), que constantemente as condicionam, possibilitam e interpelam.

\section{AGRADECIMENTOS}

Agradeço as leituras atentas e os comentários realizados sobre o manuscrito por parte de meus amigos e colegas: André Gil (Universidade Federal Fluminense), Ana Gretel Echazú (Universidade de Brasília) e Ana Laura Ossola (Universidad Católica de Salta).

\section{REFERÊNCIAS}

MESSINEO, Cristina. Lengua toba (guaycurú). Aspectos gramaticales y discursivos. Munich: LINCOM Europa Academic Publisher, 2003. (LINCOM Studies in Native American Linguistics, 48).

MILLER, Elmer. Los Tobas argentinos: armonía y disonancia en una sociedad. México: Editorial Siglo XXI, 1979.

TAMAGNO, Liliana. 'Nam Qom Hueta'a na Doqshi Lma'. Los tobas en la casa del hombre blanco. Identidad, memoria y utopía. La Plata: Ediciones Al Margen, 2001.

WRIGHT, Pablo. Histories of Buenos Aires. In: MILLER, Elmer (Ed.). Peoples of the Chaco. Westport: Bergin \& Garvey, 1999. p. 135-156.

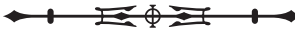


